\title{
CRUZANDO FRONTERAS. LA REFORMULACIÓN DE LA LATINIDAD AL NORTE DEL RÍO GRANDE
}

\author{
POR \\ MARÍA JESÚS CRIADO \\ Universidad Complutense de Madrid
}

En este texto se describe la evolución y características de la población de origen hispano residente en los Estados Unidos. A partir de datos oficiales y otras fuentes secundarias se detalla y analiza su desarrollo en las últimas décadas y las principales tendencias observadas. Ello nos permitirá esbozar el perfil prevalente de este variado conjunto, su posición social y los procesos en los que están inmersos. Las dinámicas generadas afectan a ambos polos (inmigrados y sus descendientes y el orbe estadounidense) y apuntan a una reformulación de la latinidad en dicho contexto.

PALABRAS Clave: Migración internacional, población hispana, asimilación, pluralidad cultural, Estados Unidos, América Latina.

\section{INTRODUCCIÓN. LA NUEVA NACIÓN LATINA}

Los latinos o hispanos — del inglés hispanics, término que designa al segmento de población que refiere su origen o raíces al orbe hispanohablante son una presencia de larga data en los Estados Unidos; anterior, en algunos casos, a su fundación como nación. Pero hasta hace poco parecían sentenciados a un papel marginal en los anales; relegados por un sistema social que orilla los efectos de la desigualdad y estigmatiza al desfavorecido, y sujetos a una larga crónica de discriminación, carencias y prejuicios. Su evolución reciente los saca de la sombra para recuperar y reinventar un lugar como sujetos de la historia.

Reconocida oficialmente en 2001 como la minoría más cuantiosa, en julio de 2007 superaban holgadamente los 45 millones — sin incluir la población de 
Puerto Rico ${ }^{1}$ - , cinco veces más que en 1970, cuando se les empezó a contabilizar como categoría independiente. Estados Unidos se ha convertido así, en muy breve plazo, en el segundo país en población latina, sólo por detrás de México, el principal referente, a su vez, de tan voluminoso conjunto. Y, según las proyecciones oficiales, a mediados de siglo uno de cada tres habitantes del país -133 millones, el 30,3\% - será de origen latino ${ }^{2}$. Una evolución que tendrá un fuerte eco en la estructura demográfica al coincidir con un paulatino declive de la población eurocaucásica, o «blanca no-hispana», término oficial. Para entonces, de cumplirse los cálculos, la última categoría reunirá menos de la mitad de la población ${ }^{3}(46 \%)$ y habrá dejado atrás su secular condición de mayoría. Estados Unidos se habrá transformado así, en unas décadas, en un país de minorías.

Detrás de este notable desarrollo se hallan varios factores demográficos: la crecida migración desde América Latina a partir de 1980, que se acelera desde 1990; una natalidad más elevada, y la estructura de edad de los latinos que favorece el ritmo de las otras variables.

Esta suma de factores ha convertido a este conjunto en la principal fuente de crecimiento poblacional de los Estados Unidos. De 1990 a 2000, los hispanos aportaron el 40\% del ascenso observado en la década (13 millones de los 33 añadidos en total), y de 2000 a 2007 generaron la mitad. De los 20,2 millones que aumentó la población estadounidense en dicho período, 10,2 millones eran de origen latino ${ }^{4}$, aporte muy significativo y que avala la fuerza de su impulso. Más, si se tiene en cuenta que su peso relativo en el conjunto, aunque en aumento, aún sigue siendo relativamente menor (15\% en 2007).

Los efectos de este desarrollo, que comparten, aunque en menor grado, otros flujos y minorías, inciden en la estructura demográfica de la nación y su presencia se hace sentir en muchas otras áreas (mercado laboral, esfera educativa, consumo, política, medios, etc.). Mientras su influjo a nivel cultural se refleja no sólo en el ascenso de la música latina o de nuevos usos culinarios. Aún más relevante será el avance que observa la lengua española que, con cerca de

1 Cerca de cuatro millones (3.942.375) a 1 de julio de 2007 (Oficina del Censo de los Estados Unidos, 2008a).

2 Oficina del Censo de los Estados Unidos, 2008c.

3 Oficina del Censo de los Estados Unidos, 2008a.

4 Este aporte se compone casi a partes iguales de un crecimiento vegetativo muy significativo (unos seis millones, casi la mitad del totalizado por el país en esa rúbrica) y una migración neta aún importante (4,2 millones de 2000 a 2007, algo más de la mitad del cómputo total en esa partida, en torno a ocho millones) (Oficina del Censo de los Estados Unidos, 2008a, Tabla 5). 
35 millones de hablantes en $2007^{5}$, el $12 \%$ de la población, se ha convertido, de hecho, en el segundo idioma del país.

Este proceso de trasvase y asentamiento de población latinoamericana en suelo estadounidense repercute a su vez en los lugares de origen, en donde los emigrados se han convertido en agentes activos que impulsan el desarrollo socioeconómico e inciden a nivel político. Es la dimensión transnacional de las corrientes migratorias que, aunque esté lejos de ser un fenómeno nuevo, en las condiciones presentes, adquiere un rango que no tuvo antes. La región del ALCA (América Latina y el Caribe) es la principal receptora de remesas a nivel mundial (61,1 millardos de dólares en 2007, según datos del Banco Mundial $^{6}$ ), procedentes, en gran parte (más del $70 \%$ ), de los emigrados a Estados Unidos. Éstas constituyen un importante sostén para muchas de las economías del área, tanto en términos absolutos (México con más de 25 millardos de dólares en 2007, detenta la tercera posición en recepción de remesas) como por su contribución al PIB de un cierto número de países (en Honduras y El Salvador, p. e., supusieron, en 2007 , el $24,5 \%$ y el $18,4 \%$, respectivamente, en términos del PIB).

Pero el avance efectivo de la población hispana no elimina las carencias que limitan a un buen número de sus miembros, ni las adversas condiciones que determinan sus oportunidades y condiciones de vida. Déficit educativo y de cualificación, desempleo, salarios escasos, pobreza y marginación, siguen configurando el horizonte de vida de muchos latinos; al igual que persisten los estereotipos y prejuicios que vejan su imagen y la hostilidad que han padecido históricamente. Un poderoso movimiento antiinmigración y otro de corte «esencialista», que demandan el cierre a cal y canto de fronteras y la proscripción de las lenguas vernáculas de la esfera pública, tienen como principal o único objetivo a la población hispana. Con ello, canalizan la tradicional animosidad existente.

En las siguientes páginas revisaremos algunos de estos aspectos. Aunque lo primero a subrayar es que los hispanos no son, ni fueron nunca, un bloque unitario. Muchos incluso rechazan o cuestionan ese título. Unos, al vincularlo a la colonización. Otros, por el sesgo que introduce al laminar, en un solo rótulo, la pluralidad que congrega, diversidad que se hace explícita en la suma de orígenes (nacionales, de clase, de emigración), estatus, perfiles, generaciones o trayectorias que se subsumen bajo una etiqueta reduccionista y angosta; si bien, también resume el único elemento que los une a todos: la inscripción en

5 Oficina del Censo de los Estados Unidos, 2008b.

6 Banco Mundial, 2008 (cifra estimada a partir del Anuario Estadístico de la Balanza de Pagos 2008 del FMI). 
una misma cultura, explícita en una lengua franca y una tradición religiosa. Aunque no todos hablan español y entre ellos aumentan los miembros de otras confesiones, ésta será la rúbrica en la que se reconozca, o remita sus raíces, la generalidad.

Una relativa unidad cultural trabada en la urdimbre de la diferencia es, pues, la seña genérica que va a definir a los hispanos. Ambas están unidas a las trayectorias históricas de los contextos de origen que segmentan al conglomerado y dan cuenta a su vez del momento y de la evolución del marco en el que se insertan. En los albores del siglo XXI, este conjunto está en el vértice de un amplio proceso que incorpora nuevos elementos en las comunidades que lo conforman ${ }^{7}$ así como en el contexto en el que tienen lugar esas dinámicas, $\mathrm{y}$ que, muy plausiblemente, dará lugar a un nuevo crisol.

\section{LA POBLACIÓN HISPANA EN EL CONTEXTO ESTADOUNIDENSE: RASGOS Y TENDENCIAS}

A continuación se describe a grandes rasgos las tendencias generales observadas en este agregado en varias dimensiones que contribuyen a darle impulso y forma: demografía, mercado, electorado (potencial), lengua e identidad. La combinación de esos trazos esboza una determinada semblanza del conjunto y le otorgan carices específicos que suelen encubrir la pluralidad que congrega la generalidad de los grupos, tanto a nivel interno como entre sí.

\subsection{El factor demográfico: Inmigración y población}

La última década del siglo XX fue decisiva en el desarrollo y la visibilización de la población latina. En ella se hizo evidente su potencial de crecimiento, vía inmigración y natalidad; se incorporaron nuevos flujos, añadiendo más número y diversidad; y afloró una nueva tendencia en la pauta de asentamiento que se materializó en un gradual despliegue en el territorio. Su designación oficial el 21 de enero de 2003 como la minoría más cuantiosa de la nación, a

7 En la evolución, configuración e imagen social de la población latina como entidad unificada confluyen una variedad de factores y procesos que contribuyen a conformarla e instituirla en cuanto tal. Éstos refieren a tres cauces distintos: a) La constitución en el tiempo y precipitación subsiguiente de una mezcla de población, fruto del aluvión demográfico e histórico; b) Su unificación en una categoría administrativa que la formula con sus correlatos estadísticos; y c) Un sustrato cultural común y una historia (hasta cierto punto) compartida, que le otorga plausibilidad, unido a la suma de intereses a los que sirve (véase Portes, 2004. Criado, 2006). 
1 de julio de 2001, ratificó el alcance del cambio demográfico y el efecto de estos procesos.

En efecto, entre 1990 y 2000 la población hispana aumentó unos 13 millones (de 22,4 millones a 35,3 millones), un incremento cercano al 60\%, casi 4,5 veces más que la población estadounidense en su conjunto $(13 \%)$ y cerca de siete veces el de la población no latina. Su efecto en la población total fue rotundo al aportar casi la mitad de los 33 millones que añadió ésta en el período. Esa misma dinámica ha continuado en la presente década corroborando su potencial de desarrollo y la creciente importancia - presente y futura - de este segmento en la demografía de la nación (véase tabla 1).

La celeridad de esta espiral se refleja en su cuota en la población que superaba en 2007, el 15\%, nueve puntos porcentuales más que en $1980(6,4 \%)$ y seis más que en 1990 (9\%) (Tabla 1). Expresado en términos numéricos significa que, si en 1980, sólo uno de cada quince residentes en suelo estadounidense era latino y en 1990, lo era uno de cada once, en 2007, casi uno de cada seis se incluye en esa categoría. La progresión es, pues, muy acelerada y la previsión es que lo seguirá siendo. Ello, unido a las dinámicas que presentan, a su vez, los otros segmentos de población, está teniendo $-\mathrm{y}$ tendrá- un fuerte impacto en la composición y estructura étnica de la nación.

TABLA 1. EVOLUCIÓN DE LA POBLACIÓN SEGÚN GRUPOS RACIALES Y ORIGEN HISPANO. 1990-2007

\begin{tabular}{|l|r|r|r|r|r|r|r|r|}
\hline & \multicolumn{3}{|c|}{ Población (millones) } & \multicolumn{3}{c|}{$\begin{array}{c}\text { Tasa en la población } \\
\text { (\%) }\end{array}$} & \multicolumn{2}{c|}{ Variación (en \%) } \\
\cline { 2 - 9 } & \multicolumn{1}{|c|}{1990} & \multicolumn{1}{|c|}{2000} & \multicolumn{1}{|c|}{2007} & 1990 & 2000 & 2007 & $1990-2000$ & $2000-2007$ \\
\hline Total EEUU & 248,7 & 281,4 & 301,6 & 100,0 & 100,0 & 100,0 & 13,1 & 7,2 \\
No-Latinos* & 226,4 & 246,1 & 256,1 & 91,0 & 84,9 & 84,9 & 8,7 & 4,1 \\
Blanca & 188,1 & 195,6 & 199,1 & 75,6 & 69,5 & 66,0 & 4,0 & 1,8 \\
Afroamericanos & 29,2 & 34,3 & 37,0 & 11,7 & 12,3 & 12,3 & 17,5 & 8,0 \\
Asiática & 7,0 & 10,4 & 13,1 & 2,8 & 4,3 & 4,3 & 48,6 & 25,8 \\
Otros no hispanos & 3,1 & 5,9 & 6,9 & $1,2 \%$ & 2,1 & 2,3 & 89,4 & 17,7 \\
Hispanos o latinos & 22,4 & 35,3 & 45,5 & 9,0 & 12,5 & 15,1 & 57,9 & 28,9 \\
\hline
\end{tabular}

* Las categorías en los «No-latinos» refieren a grupos raciales simples.

Fuente: Oficina del Censo de los Estados Unidos: Censo 1990, Censo 2000 y Encuesta de la Comunidad Estadounidense 2007. Cálculos propios.

El motor fundamental del ascenso ha sido hasta hace muy poco la inmigración y, en cierto modo, aunque sea indirecto, lo sigue siendo pues el nuevo factor - la natalidad - guarda relación con ese proceso debido al impacto 
añadido de los flujos en la estructura de edades. La acumulación de efectivos en la edad laboral, que coincide con la etapa reproductora, tiene así un efecto directo en la evolución de los nacimientos. Un estudio del Center for Migration Studies, entidad que aboga por una reducción de la migración, corrobora este factor al examinar la aportación de las inmigrantes a la natalidad nacional entre 1970 y $2002^{8}$. Según este estudio, que cifraba en más de 915.000 el total de alumbramientos debidos a este segmento en 2002 (el 23\% del total de nacidos en el país), las latinas contribuyeron en cerca de dos tercios (59\%) a esa categoría. Las inmigradas mexicanas aportaron en ese año, según el citado estudio, alrededor de la mitad (45\%) de los nacimientos habido en ese rango. La evolución respecto a décadas previas es manifiesta: en 1980 la contribución de las inmigradas latinas a este nivel no llegó a la mitad (45\%), quince puntos porcentuales menos.

Y es que hablar de inmigración en Estados Unidos, al igual que cualquier otro tema que incumba a la población, es hablar de latinos. Más de 20 millones en 2007 — casi la mitad de la población hispana_, eran inmigrantes. Su cifra ha crecido de forma sostenida en las últimas décadas doblando aproximadamente sus efectivos de una a otra como se puede ver en los gráficos 1 y 2. Éstos dominan el flujo procedente de Latinoamérica y Caribe, al que de modo regular se identificará con ellos. En conjunto, los naturales de esa región (hispanos y no hispanos) suponen más de la mitad de los inmigrados. Su cuota se ha incrementado de forma constante desde 1970, fecha que marca un punto de inflexión en la actual fase migratoria ${ }^{9}$. Desde entonces la población foránea ha ascendido velozmente, con los flujos latinos a la cabeza, y superaba los 38 millones en 2007 (el 12,6\% de la población). En 1990 eran 8,4 millones (el 44\% de los foráneos); diez años antes representa-

8 Camarota, 2005.

9 En ello fue decisivo el cambio de política migratoria adoptado en 1965 e inscrito en la ola de reformas vinculadas al movimiento de derechos civiles. El nuevo marco sustituye el modelo basado en la nacionalidad, vigente desde 1921 y muy restrictivo, por el modelo actual de distribución de visas en función de los criterios de «reagrupación familiar», «habilidades profesionales» y «asilo político». Ello no sólo posibilitó un cambio de tendencia en el stock de inmigrantes, que alcanzó la cota más baja de la historia en 1970 (menos del 5\% de la población); también abrió la puerta al cambio demográfico al dar entrada a un nutrido flujo de América Latina y de Asia. La reagrupación familiar será decisiva para el primero al posibilitar la migración en cadena. Asiáticos y otros grupos, más distantes geográficamente y con una base de partida mucho menor, se valen, en mayor medida, de la cualificación. Ello explica las enormes diferencias entre la población latina, en conjunto, y la asiática o la africana, que destacan, frente al resto de categorías, incluida la dominante, por su elevada capacitación. 
ban un tercio, y menos de un quinto en 1970. La escalada no puede ser más nítida.

Gráfico 1. Población extranjera en los EEUU SEgún Área de origen. 1960-2007

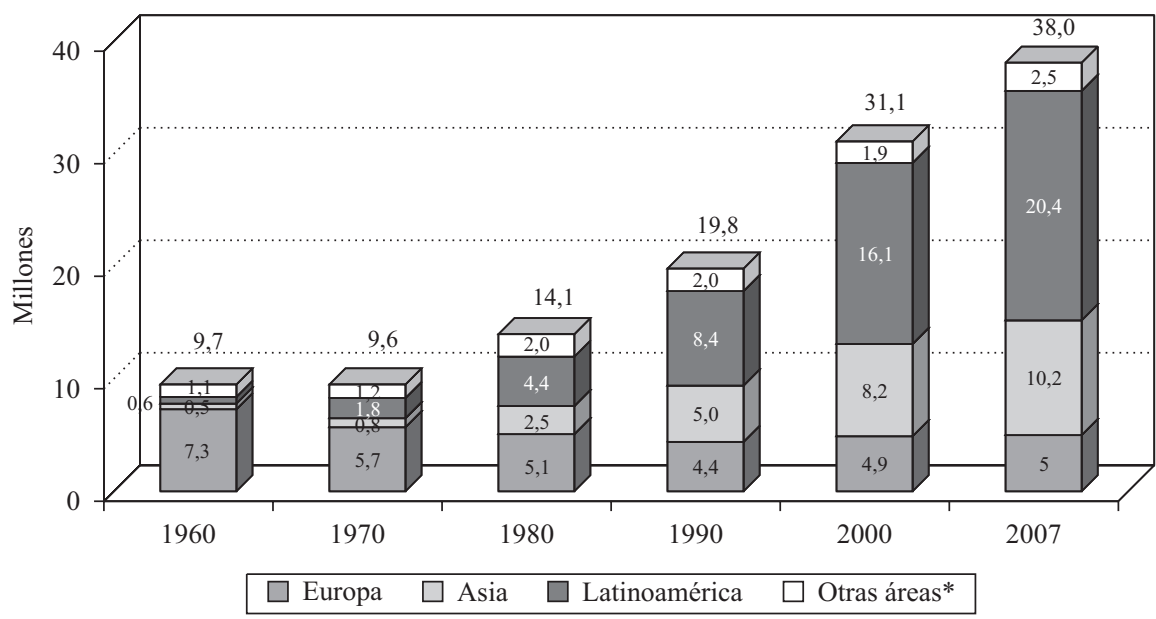

«Otras áreas» comprende: África, Oceanía, Norteamérica y los no especificados.

Fuente: Para 1960 a 1990. Gibson y Jung, 2006; para 2000 y 2007, Censo 2000 y American Community Survey, 2007, Oficina del Censo de los EEUU. Elaboración y cálculos propios.

Los cambios habidos a este respecto han trastocado totalmente la estructura previa. El contingente europeo, tradicionalmente hegemónico, se ha ido reduciendo, por la desaparición de sus miembros y la ausencia de reemplazos y perdiendo posiciones en el conjunto. Mientras el resto, en particular latinos y asiáticos, han aumentado de forma considerable su representación tanto en términos absolutos como relativos. En cada década, a partir de 1960, los latinos han constituido la mitad de los inmigrantes documentados, cifra a la que hay que añadir la de los irregulares, una categoría que empezó a adquirir peso en la década de 1980 y que concentra una elevada suma. Son también los latinos quienes acumulan menos tiempo de estancia en el país de todos los colectivos pues el grueso llegó a partir de 1990 (12,2 millones, el $60 \%)^{10}$.

10 Oficina del Censo de los Estados Unidos, 2008b. Cálculos propios. 
Sólo dos grupos, mexicanos y puertorriqueños, cuya historia en Estados Unidos se remonta más atrás en el tiempo tienen mayor representación de nativos que de inmigrados entre sus miembros. En uno y otro, los nativos rondan el 60\%. En el resto de nacionalidades dominan los foráneos. Entre los cubanos, uno de los flujos que se anticipó al aluvión general de las últimas décadas, la segunda y ulteriores generaciones representan alrededor de un tercio del total. Una distribución muy similar a la que presenta el colectivo dominicano que cuenta también con una primera oleada a mediados de los sesenta. En las demás nacionalidades, los inmigrados superan las tres cuartas partes.

Gráfico 2. Evolución de la POBlación LATina SEGún NATALidAD. 1970-2007

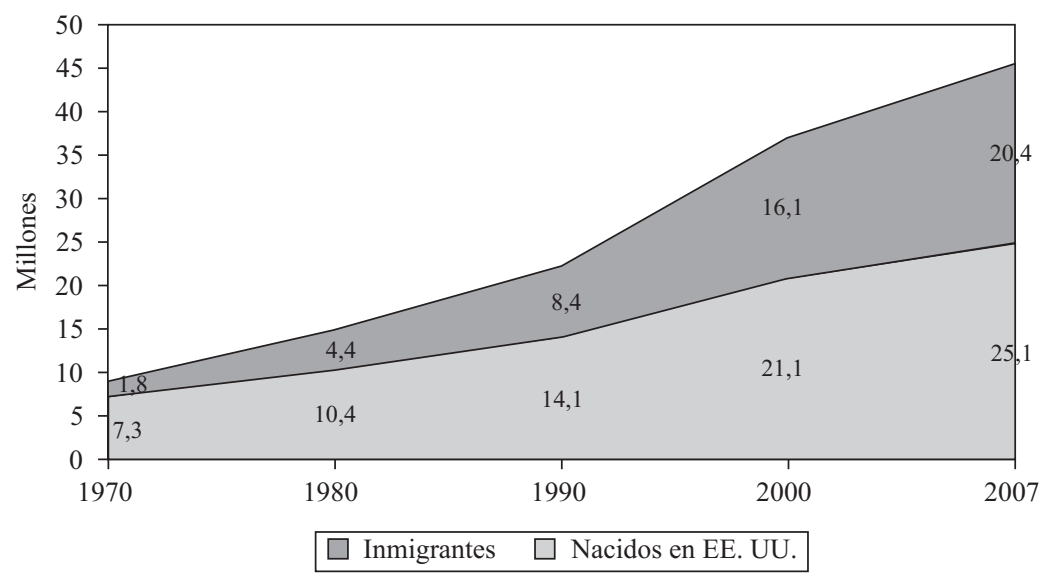

Fuente: Gibson y Jung, 2002; 2006. Oficina del Censo de EEUU, 2008a; 2008b. Elaboración propia.

Estos dos hechos, predominio de la primera generación en la estructura generacional y lo reciente de la inmigración, distinguen a la población hispana del resto de grupos y le confieren, a su vez, un perfil distintivo. Ambas ayudan a entender el proceso en el que se hallan inmersos, sus principales rasgos y condiciones. Pues indican, para empezar, que, en una gran parte, afrontan las dificultades y condicionamientos que conlleva el hacerse la vida en un país distinto, acentuadas, normalmente, en las primeras fases del asentamiento. A ello se une la importancia de la inmigración indocumentada en la población hispana, condición que se ha ido acentuando y que agudiza los obstáculos y grava sus oportunidades y condiciones de vida. 
Cuatro de cada cinco indocumentados procede de Latinoamérica ${ }^{11}$. En 2008, su cifra se estimaba en 9,6 millones, más del $80 \%$ del conjunto total (11,9 millones). Sólo los nacionales de México sumaban siete millones, mientras del resto de la región procedían otros 2,6 millones. Detrás de este incremento de la inmigración irregular está la dependencia estructural de la economía estadounidense de una mano de obra barata y poco cualificada, las carencias del sistema para regular el flujo (insuficiente número de visas, excesiva demora en la tramitación de la reagrupación familiar, etc.) y el énfasis en el control fronterizo, que añade cada vez más riesgos y encarece el paso y, como consecuencia, convierte la emigración circular - tradicional en el flujo mexicano- en permanente ${ }^{12}$.

La situación de irregularidad no sólo afecta a los miembros adultos, también incide, y muy especialmente, en los jóvenes y los menores que crecerán en unas condiciones más difíciles. Un estudio del Centro Pew Hispanic ${ }^{13}$, estimaba en unos 14 millones la cifra de latinos que vivían, en 2004, en hogares que contaban entre su miembros con algún indocumentado. Entre éstos se incluían más de un millón y medio de menores en tal condición y otros dos millones y medio aproximadamente de nativos (y ciudadanos, por tanto) estadounidenses.

Ésta será, pues, otra de las señas de la inmigración hispana y una de las que más cala en el imaginario colectivo delimitando su imagen con las connotaciones negativas que suele llevar anejas.

Los mexicanos no sólo constituyen el principal segmento en esta rúbrica; también es el contingente más voluminoso, con gran diferencia, de todos los foráneos y, por ende, en la emigración latinoamericana. Su cifra en 2007 se aproximaba a los 12 millones (el 31\% del total), más que el agregado de inmigrantes asiáticos (10,2 millones), la segunda región en orden de importancia, y la suma conjunta del resto de flujos de su área de referencia $(8,7$ millones en 2007) $)^{14}$. La segunda nacionalidad más voluminosa, los originarios de China, no llegaba a dos millones. Es un dato más que ayuda a hacerse una idea del peso que supone el contingente mexicano en el conjunto migrante, en general, y en el latino, en particular, convirtiéndole en su cara más visible.

11 Passel y Cohn, 2008. Hoefer, Rytina y Baker, 2008.

12 Massey, Durand y Malone, 2002.

13 Passel, 2005.

14 La diferencia se acentúa aún más, si sólo tenemos en cuenta a los agregados que procedían del orbe hispanohablantes, que en 2007 congregaban, en conjunto, unos 6,4 millones en total, según cálculos propios a partir de los datos de la Encuesta de la Comunidad Estadounidense 2007 (Oficina del Censo de los EEUU, 2008b). 
Detrás de la inmigración latinoamericana a los EEUU se observan, según Suárez-Orozco ${ }^{15}$, tres cuadros sociales: un flujo a gran escala, más o menos regular, desde México que se intensifica a partir de 1980; oleadas puntuales desde América Central y del Sur, unidas con frecuencia a conflictos políticos y otra serie de crisis; y un patrón caribeño de migración circular tipificado en las experiencias de puertorriqueños y dominicanos. Las condiciones estructurales - efectos de la globalización y reestructuración económica en los países emisores y dependencia de la economía de EEUU de la mano de obra migranteapuntan a una continuidad de los flujos desde esas latitudes. De modo que, aun en el caso de un eventual descenso, los latinoamericanos seguirán siendo dominantes. Y así lo contemplan las últimas proyecciones a este respecto de la Oficina del Censo, que atribuye a este segmento la mitad de la migración neta que se incorporará al país en la primera mitad del presente siglo. En cifras absolutas, y a tenor de esos cálculos, ello supondrá cerca de 40 millones de inmigrantes más que se añadirán, de 2001 a 2050, contribuyendo a engrosar más este nutrido contingente ${ }^{16}$.

\section{Orígenes nacionales}

Los procesos históricos y la relativa proximidad geográfica repercuten en el tamaño de los grupos. No es extraño, pues, que el papel protagonista incumba al origen mexicano, el más próximo geográficamente y el que remonta más lejos los vínculos históricos. Su hegemonía es manifiesta en todas las rúbricas: en el cómputo total, en el de inmigrantes y dentro de éstos, como acabamos de anotar, entre quienes carecen de los permisos pertinentes. La distancia numérica es tan notoria que traslada al conjunto de la región sus señas características. La imagen que resulta así, a escala genérica, es fiel reflejo del conjunto mexicano. Y es que dos de cada tres latinos (64\%), más de 29 millones en 2007, remiten su origen o herencia al país colindante al Río Grande. Frente a ello poco puede hacer la variedad que congrega la suma de nacionalidades restantes (gráfico 3).

Son los mexicanos, además, quienes aportaron, como refleja el gráfico 3, el grueso de los agregados en estas décadas. En concreto, de 1990 a 2007, duplicaron su volumen añadiendo con ello dos de cada tres de los incorporados al conjunto total en el período. De ahí que, aunque el resto de grupos, vayan aumentando en volumen, la polarización nacional sigue siendo la pauta más distintiva.

15 Suárez-Orozco, 2001.

16 Oficina del Censo de los Estados Unidos, 2008b. Cálculos propios. 
Gráfico 3. EvoluCión de LA POBlación LATINA SEGÚN ORIGEN NACIONAL. 1990-2007

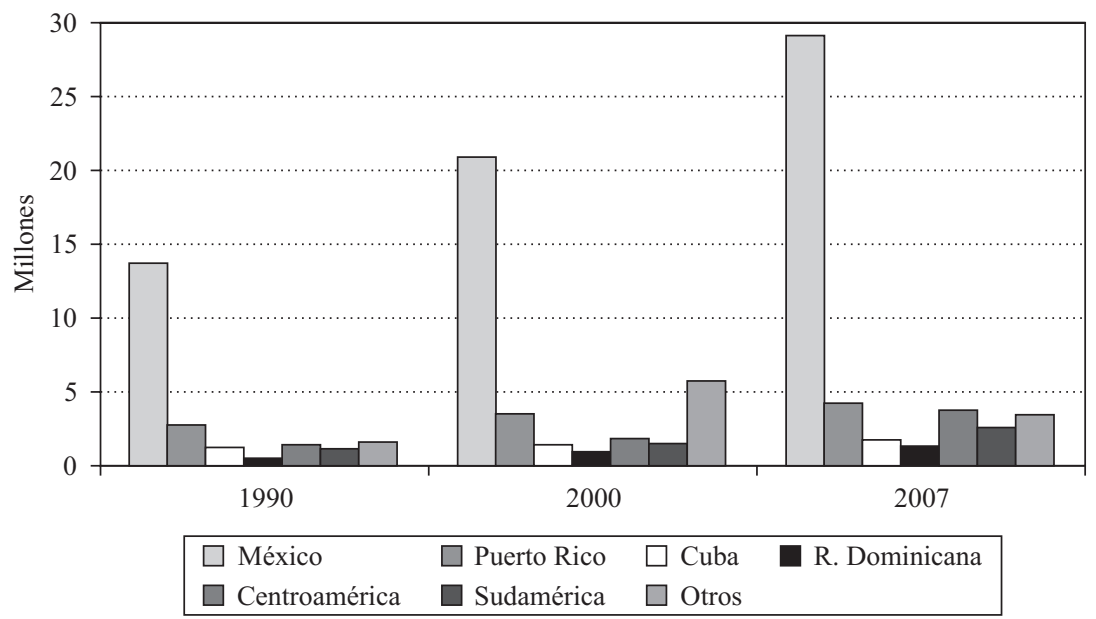

Fuente: Oficina del Censo de los EEUU, Censo 1990, Censo 2000 y Encuesta de la Comunidad Estadounidense 2007. Cálculos propios.

La incorporación de nuevos flujos y el aumento de los menores, los nuevos latinos, como se les denominó al principio de esta década para remarcar dicho rasgo, fue una de las novedades de la pasada década. Ello añade, ya lo hemos señalado, más diversidad $\mathrm{y}$, aunque su influjo no sea muy perceptible a nivel general, al ser cifras relativamente pequeñas, sí empiezan a tener cierta influencia a escala local. Los mexicanos, reforzados ahora por el resto de nacionalidades de Centroamérica, siguen siendo la cara más visible del conjunto. Pero, a los otros dos grupos tradicionales — puertorriqueños y cubanos-, sí les ha afectado el cambio y han reducido ligeramente su cuota en el agregado. A la vez van a advertir, en esferas concretas (influencia política, mercado laboral, prestaciones sociales, etc.) la presencia de los recién llegados. Salvadoreños (1,5 millón en 2007), dominicanos (1,2 millón), guatemaltecos ( 0,9 millón) y colombianos ( 0,9 millón), los más numerosos de los nuevos flujos, empiezan a tener una cierta presencia en las áreas en las que residen.

Por otra parte, si los factores implicados auguran larga vida al sistema migratorio, la juventud y elevada natalidad de la población aseguran la tendencia ascendente del conjunto. De hecho, como ya se avanzó, la reproducción ha sustituido a la migración como la principal fuente de crecimiento. Así, de los diez millones que agregó la población hispana de 2000 a 2007, casi dos tercios (unos seis millones) se debió al crecimiento natural (diferencia entre naci- 
mientos y defunciones), mientras la migración neta, aunque sigue siendo alta (4,2 millones en ese lapso), aportó el $40 \%$ del total añadido.

Las mujeres hispanas, foráneas y nativas, detentan la natalidad más elevada de todos los grupos. En 2000 la tasa global de fecundidad estimada (o número medio de hijos por mujer) fue de 3,4 hijos en las inmigrantes hispanas frente a 1,8 en las de otros orígenes. En conjunto, esto es, incluyendo a las nativas, superaban holgadamente — con 2,7 hijos- el nivel de reemplazo generacional $(2,1)$ a una notable distancia de la media nacional situada ese año en 2,0 . Los datos de 2005 ratificaban la solidez de esta pauta que ofrece un marcado contraste respecto a los otros sectores y, en particular, con el eurocaucásico. La tasa total de fecundidad en este último en ese año fue de 1,8 hijos por mujer, frente a los 2,9 de las mujeres hispanas ${ }^{17}$.

La acusada juventud de esta población unida a esta pauta demográfica augura un crecimiento sostenido. Así lo corroboran las proyecciones de la Oficina del Censo para las próximas décadas que atribuyen al saldo vegetativo la mayor cuota en el aumento de la población $(60 \%)$, fruto de un abultado monto de nacimientos (74,5 millones de 2001 a 2050 , un tercio de los previstos en total en la nación) y una escasa cifra de defunciones (unos 17 millones, el 10,6\% de la cifra total estimada) ${ }^{18}$. Estos datos dan cuenta del alcance del efecto combinado de ambas variables (edad y natalidad) a largo plazo.

La estructura de edad de la población latina es otro de los indicadores que sostiene el escenario demográfico en ciernes. Ésta ostenta el perfil más joven de todos los segmentos de población de los que se distancia en todos los rangos, y aún más, del eurocaucásico, como muestra la tabla 2. La mediana de edad - 27,6 años en 2007- destaca frente a los otros grupos, al igual que la de la población blanca no hispana, aunque en sentido inverso: juventud vs. madurez; con cerca de 41, esta última rebasaba en catorce años a la primera. El contraste es patente en los distintos intervalos. Uno de cada tres latinos era menor de 18 años (34\%), el 11\% no había celebrado aún el 5..$^{\circ}$ aniversario (la tasa más alta de preescolares); uno de cada cinco (22\%) contaba más de 45 años y sólo un 5,5\% superaba los 65 años. Unos datos que difieren de los índices medios que dibujan el perfil general de toda la población y aún más cuando se cotejan con los del sector mayoritario (blancos no-hispanos) que evidencia los signos propios del proceso de envejecimiento (véase tabla 2).

La concentración en la edad laboral y en los peldaños bajos de la escala muestra, de un lado, el peso de la inmigración y, de otro, la fecundidad de las

17 Bachu y O’Connell, 2001, «Vital Statistics, 2007», U.S. Census Bureau, 2007.

18 Oficina del Censo de los Estados Unidos, 2008c. Cálculos propios. 
mujeres latinas. Ambas avalan las perspectivas de crecimiento de la población latina y son fuente de atención por sus implicaciones a largo plazo al nutrir y avalar la evolución de los nativos.

TABla 2. EdAd SEgún RAZA y ORIGEN HiSPANO (en \%). 2007

\begin{tabular}{|l|c|c|c|c|c|c|c|c|c|}
\hline & \multirow{2}{*}{ Total } & \multicolumn{4}{|c|}{ Menos de 18 años } & \multicolumn{3}{|c|}{18 y más años } & \multirow{2}{*}{$\begin{array}{c}\text { Mediana } \\
\text { (años) }\end{array}$} \\
\cline { 3 - 10 } & & Total & $<$ de 5 & 5 a 13 & 14 a 17 & Total & 18 a 64 & 65 y & \\
\hline Total población & 100,0 & 24,5 & 6,9 & 11,9 & 5,7 & 75,5 & 62,9 & 12,6 & 36,6 \\
Blanca-no hispanos & 100,0 & 21,2 & 5,6 & 10,4 & 5,2 & 78,8 & 63,5 & 15,4 & 40,8 \\
Afroamericanos & 100,0 & 29,4 & 8,1 & 14,1 & 7,1 & 70,6 & 62,3 & 8,3 & 31,1 \\
Asiáticos & 100,0 & 25,4 & 7,7 & 12,3 & 5,3 & 74,6 & 66,0 & 8,6 & 33,9 \\
Hispanos/Latinos & 100,0 & 33,9 & 10,8 & 16,3 & 6,8 & 66,1 & 60,6 & 5,5 & 27,6 \\
\hline
\end{tabular}

Fuente: Oficina del Censo de los EE.UU., 2008 a. Elaboración propia.

Esos mismos factores tendrán efectos también a escala escolar en donde los estudiantes latinos conforman hoy un nutrido grupo y constituyen el sector en mayor ascenso. Según el informe anual del Centro Nacional de Estadísticas Educativas, The Condition of Education $2008^{19}$, uno de cada cinco matriculados $(20 \%)$ en las escuelas públicas de la nación en 2006 era de origen hispano (cerca de 10 millones). En 1972, suponían el 6\% de los escolares y el 11\% en 1986, lo que da cuenta del impulso observado. Éste es más patente en los Estados y distritos escolares de mayor concentración que presentan tasas mucho más consistentes. El ámbito escolar, neto indicador del futuro, se está, pues, latinizando.

\section{La «geografia» hispana}

Tradicionalmente, los hispanos se han concentrado en determinadas zonas del país y, en particular, en el sudoeste. Allí residían en 2007, cuatro de cada cinco hispanos, cifra suficientemente indicativa de esta pauta y que contrasta con la genérica del segmento mayoritario, con una distribución regional más nivelada. De ahí que su tasa en la población difiera notablemente de una a otra área: del 42\% en el Oeste, que albergaba en 2007 a más de 19 millones, al 9\% en la región interior (Medio Oeste) en donde residían unos cuatro millones. Tanto en esta última como en las restantes, su cuota en la población se ha incrementado notablemente en las últimas décadas. Esta distribución, tan asimé-

19 Planty, 2008. 
trica, tiene su razón de ser inicial en los antecedentes históricos de esas áreas, su vecindad con México y resto de países emisores y, por supuesto, las oportunidades laborales.

La concentración es, por otra parte, uno de los rasgos habituales en los procesos migratorios y, más aún, en la etapa inicial cuando el apoyo de conocidos y familiares es decisivo. No es extraño, pues, que ésta se avenga a una pauta colectiva generando con ello diversos enclaves, indicativos, en parte, de un doble proceso selectivo que acaba ligando, en ocasiones, una determinada circunscripción a un colectivo. Y así ocurre, en gran medida, con la población latina. El sudoeste ha sido, y sigue siendo, en gran medida, el lugar privilegiado por los mexicanos. Los puertorriqueños, en cambio, han venido congregándose en el noreste, en particular en Nueva York, aunque están empezando a adquirir cierta importancia en la Florida. Este último estado es, a su vez, el núcleo central de asentamiento de los cubanos que han logrado convertir dicho enclave en zona de referencia. La selección a nivel regional refiere, pues, a puntos concretos.

Y así, bastan siete estados, que albergan, a su vez, más de un millón de latinos, para reunir las tres cuartas partes de los mismos. Son, en orden decreciente, California (13,2 millones en 2007), Texas (8,6 millones), Florida (3,8), Nueva York $(3,2)$, Illinois $(1,9)$, Arizona $(1,9)$ y Nueva Jersey $(1,4)$. Y si se añade los otros dos que lo rondan (Colorado y Nuevo México), se alcanza el 80\%. El resto (cerca de 10 millones en 2007) se repartía de forma irregular en los 43 estados restantes con agrupaciones de relativa importancia en un puñado de ellos (Gráfico 4).

Gráfico 4. Distribución DE LA POBLACIÓN HISPANA. 1990-2007

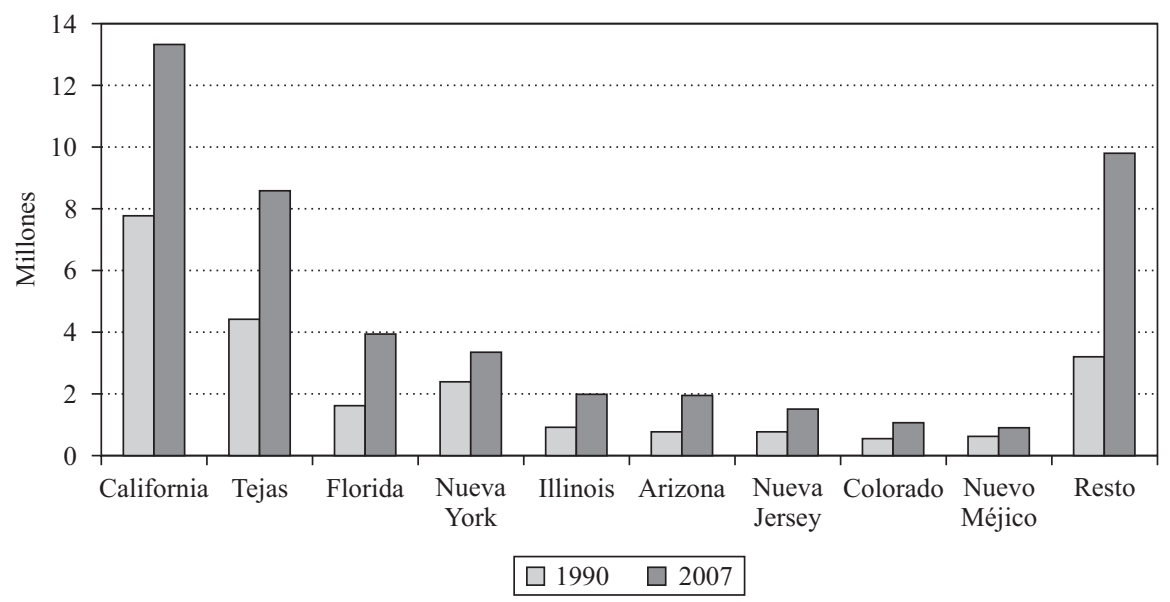

Fuente: Oficina del Censo de los EEUU, Estimaciones Anuales de la población de los EEUU 2007. 
La tasa de la población hispana en el conjunto de la población muestra también muy marcados contrastes. A nivel estatal encabeza la lista Nuevo México, en donde rondaban, en 2007, el $45 \%$ de su población. Le siguen Texas y California - los estados más poblados del país - en donde constituían más de un tercio de la población; Arizona (30\%); Nevada (25\%), que se incorpora tras el último Censo al abanico de estados hispanizados, y Florida y Colorado, en donde constituyen cerca del $20 \%$ de la población. Son tasas importantes, aunque es a nivel local en donde se hace más explícito el desarrollo de población hispana. Así, en algunos lugares, como el Este de los Ángeles (California), Laredo y Brownsville (Texas) o Hialeah (Florida), es latina la generalidad de sus habitantes (más del 90\%). En El Paso (Texas) superaban, en 2007, el 80\%, mientras en Miami-Dade (Florida), con cerca de 1,5 millón, rondaban los dos tercios en dicha fecha, y en el condado del Bronx (Nueva York), donde contabilizaban más de 700.000 , rebasaban el $50 \%{ }^{20}$.

Fuera de los citados, hay concentraciones significativas en algunos distritos de diversos estados con escasa tradición hispana. Entre ellos, Washington, Idaho, Wyoming, Utah, Carolina del Norte, Georgia, Iowa, Arkansas, Nebraska, Minnesota, Alabama, etc. En algunos de ellos suponían entre el 6,0 y el $25 \%$ de la población total. Es ésta una de las notas más relevantes de la pasada década: la extensión a zonas ajenas, hasta ahora, a su influjo que advierten un aumento sustancial en sus efectivos. Éste supera con creces, en cifras relativas, al de los núcleos tradicionales.

De 1990 a 2007, unos veinte estados, fuera hasta ahora del círculo tradicional de asentamiento, incrementaron su población latina por encima del $200 \% \mathrm{e}$ incluso algunos — las dos Carolinas, Arkansas, Georgia, Tennessee, Nevada y Alabama y Kentucky — sobrepasaron el 300\% agregando cantidades muy significativas ${ }^{21}$.

La demanda laboral, la maduración del proceso de asentamiento, la amnistía de 1986 (que facilita la movilidad y la reagrupación familiar a los regularizados) y el clima antiinmigración, patente en alguno de los enclaves tradicionales, impulsan los nuevos emplazamientos. No se trata, asimismo, de un hecho puntual pues uno de los rasgos del nuevo patrón es el predominio de varones, lo que apunta a un mayor desarrollo a medio y largo plazo de los enclaves que se están conformando al abrir paso a los procesos de reagrupación

20 Oficina del Censo de los EEUU, 2008a.

21 En Georgia, por ejemplo, su población añadió más de 600.000 nuevos miembros en este período multiplicando por siete la cifra inicial de partida; en Nevada y en las dos Carolinas añadieron más de 400.000 (entre $360 \%$ y $621 \%$ de aumento). 
y creación de familias y al contribuir a la formación y consolidación de nuevas redes migratorias.

Hablamos, pues, de una población elevada, en crecimiento sostenido, muy concentrada y que se extiende por la geografía. Todo ello resalta la significación de la población hispana. Pues si el volumen ya alcanzado, su aumento y la reciente difusión afirman el rango y dimensión del fenómeno —al avalar la evolución futura y el alcance nacional-, la concentración tiene, a su vez, una serie de efectos - hacia dentro y hacia fuera - que afectan directamente a la dinámica social (externa e interna).

\section{LA DIMENSIÓN SOCIOECONÓMICA: UN GIGANTE CON GRANDES GRIETAS}

Es evidente que no basta con ser muchos para suscitar atención y menos aún para ejercer alguna influencia. Pero este conjunto, tan dispar en sí mismo, presenta ciertas notas que hacen que se le pueda ver $-\mathrm{y}$ autopercibirsecomo una unidad diferenciada, relegando a un segundo plano las diferencias que lo segmentan. Ello le dota de un singular atractivo para un mercado ávido de nuevas clientelas y de oportunidades de negocios.

Cuando más de 45 millones de personas pueden verse a sí mismos como una unidad, compartiendo valores, cultura, lengua y aspiraciones, las empresas pueden orientar, de modo más preciso, sus estrategias de mercado y elevar así su rentabilidad. Y aunque distintos indicadores sitúan a la población hispana en los peldaños más bajos de la escala socioeconómica, los latinos no son un bloque homogéneo e, independientemente de ello, pobres o ricos, iletrados o eruditos, todos consumen. Son los hogares más nutridos, con más hijos y mayor tasa de crecimiento. Y, aunque la media de ingresos anual en los hogares hispanos sea la segunda más baja de todos los colectivos, en proporción van a gastar más en artículos de consumo que la media nacional o cualquiera de los restantes grupos.

$\mathrm{Su}$ juventud, las perspectivas de crecimiento, el progreso económico que advierten junto a su volumen, les convierte en un sector de gran atractivo para el orbe de los negocios y en el principal dinamizador del mercado de consumo estadounidense.

En efecto, con una capacidad de consumo estimada en unos 862 millardos de dólares en 2007, más del cuádruple que en 1990, la población latina se ha convertido en una de las mayores economías del mundo. Las estimaciones del Centro Selig (Universidad de Georgia) apuntan a que en 2010 traspasará la frontera del billón de dólares, congregando en 2012 cerca del 10\% del poder adquisitivo total del país (tabla 3 ). 
Tabla 3. El mercado hispano en el ORBE EStadounidense. 1990-2012

\begin{tabular}{|l|r|r|r|r|}
\hline \multicolumn{1}{|c|}{$\begin{array}{c}\text { Capacidad de consumo } \\
\text { [en miles de millones de \$] }\end{array}$} & 1990 & 2000 & 2007 & 2012 \\
\hline Total & $4.270,5$ & $7.187,6$ & $10.006,4$ & $12.976,4$ \\
Hispanos & 211,9 & 489,5 & 861,8 & $1.261,1$ \\
No hispanos & $4.058,7$ & $6.698,1$ & $9.144,6$ & $11.715,3$ \\
\hline \multicolumn{1}{|c|}{ Cuota de mercado (en \%) } & 1990 & 2000 & 2007 & 2012 \\
\hline Total & 100,0 & 100,0 & 100,0 & 100,0 \\
Hispanos & 5,0 & 6,8 & 8,6 & 9,7 \\
No hispanos & 95,0 & 93,2 & 91,4 & 90,3 \\
\hline
\end{tabular}

Fuente: Selig Center for Economic Growth, Terry College of Business, The University of Georgia, mayo 2007 (Humphreys, 2007).

El progreso económico de las nuevas generaciones, más educadas y que acceden, por tanto, a mejores puestos y salarios, el crecimiento acelerado de la población y el impulso empresarial, son los grandes motores de este ascenso. Si bien ese abultado potencial económico coexiste con unos ingresos inferiores a la media, significativas tasas de pobreza y cifras récord de abandono es$\operatorname{colar}^{22}$.

En efecto, de los 37,3 millones de pobres registrados en 2007 (el 12,5\% de la población), cerca de 10 millones eran latinos. Son, junto a los afroamericanos, quienes presentan las tasas de pobreza más altas de la nación y en conjunto reúnen más de la mitad de los desfavorecidos (52\%), sobrepasando ampliamente, uno y otro, su tasa a nivel general. Uno de cada cinco latinos (el $21,5 \%$ ) subsistía en condiciones muy precarias, una cuota que se mantiene con repuntes puntuales y que sólo supera la población afroamericana con una cuarta parte de sus miembros por debajo de la línea de pobreza ${ }^{23}$. Es éste un claro indicio de la brecha que separa a los colectivos más desfavorecidos de la población mayoritaria - blancos no-hispanos - y que sólo soslayan los asiáticos gracias a su sobrecualificación. Entre estos la tasa de pobreza suele rondar el $10 \%$, ligeramente por encima de los eurocaucásicos (8,2 en 2007).

$\mathrm{Y}$ es que los hispanos, aunque mejoren significativamente su tasa de empleo, desempeñan, en mayor medida, los trabajos menos cualificados y peor pagados. En ello incide el déficit educativo que arrastran y el peso de la inmigración, factor, vinculado, normalmente, a una escasa experiencia laboral y un

22 Véase, a este respecto, los datos e informes anuales que publica la Oficina del Censo de los EEUU sobre estos aspectos y las estadísticas del departamento de Educación.

23 DeNavas, Proctor y Smith, 2008. 
estatus legal desfavorable y que resulta crítico para entender las tendencias actuales a nivel laboral. Como consecuencia los ingresos son, en promedio, de los más bajos del país.

Hay, no obstante, cierta disparidad en función de la natividad al igual que se advierte diferencia entre los distintos grupos hispanos. Las primeras reflejan el efecto de aquellas variables que diferencian a inmigrantes y nativos (estatus legal, nivel educativo, destrezas lingüísticas, inserción en la corriente mayoritaria, etc.) y las segundas, remiten a los distintos grados de cualificación que prevalecen en cada grupo. Las familias cubanas, sudamericanas y españolas puntúan en los rangos más altos. Mientras las dominicanas, puertorriqueñas y mexicanas se sitúan por debajo de la media del agregado.

A pesar de este adverso cuadro, que les configura como población en riesgo, se evidencia un notable avance socioeconómico en algunas capas. Ello se refleja en una emergente clase media - profesional y empresarial- que rebate el perfil anterior e informa de este progreso. Muestra de este dinamismo es la evolución que experimenta el sector empresarial. Así, de 1992 a 1997, el número de empresas fundadas por hispanos subió un 30\% (mientras a nivel nacional lo hacían en un 7\%) y los ingresos alrededor del 50\% según datos de la Oficina del Censo. En esa fecha sumaban 1,2 millones y facturaban cerca de 200.000 millones de dólares. Un lustro después, las estimaciones provisionales de la Encuesta de Empresarios 2002 (Oficina del Censo de los EEUU, 2005) elevaban su cifra a 1.600.000. Éstas daban empleo a más de un millón y medio de personas y sus ingresos superaban los 227.000 millones de dólares. La tendencia, por tanto, es claramente ascendente.

La mayoría de las firmas hispanas son «microempresas» que dirigen su actividad a las necesidades específicas de los inmigrantes (envío de remesas y otros bienes, servicios legales, importación y exportación de productos a y desde el país, etc.). Algunas de estas actividades implican fuertes y sostenidos vínculos con el lugar de origen y constituyen, según han destacado diversos sociólogos, una forma alternativa de adaptación económica de las minorías en las sociedades avanzadas. El trabajo comparativo de Portes y colegas ${ }^{24}$ sobre transnacionalismo económico en varios colectivos latinos muestra que los empresarios transnacionales suponen una significativa proporción de los autoempleados en las comunidades inmigrantes así como la dependencia de muchas de estas empresas de la continuidad de los vínculos con los lugares de origen. Pero no sólo hay pequeño comercio. También hay algunas en segmentos competitivos.

24 Portes, Guarnizo y Haller, 2002. 
Corporaciones y entidades financieras elevan, pues, el presupuesto publicitario dedicado a este sector de población, lanzan campañas en español, cada vez más específicas, contratan para ellas a caras latinas conocidas y proporcionan sus servicios en castellano para lo que incorporan a sus plantillas a personal bilingüe. No es extraño, pues, que el sector que está viviendo una mayor revolución sea el de los media, instrumento del resto a través de la publicidad y uno de los modos en que se hace evidente la presencia hispana en EEUU. Ello no sólo extiende el uso del español a la esfera pública; también realza su faceta instrumental y hace explícito su valor de cambio, una dimensión de la que carecía hasta ahora y que puede incidir en el futuro del idioma.

La espiral demográfica, su difusión geográfica, juventud, ascenso socioeconómico, una lengua franca y un proceso de aculturación más paulatino posibilitan cierta proyección futura en los productos creados y el desarrollo de estrategias a escala nacional. En el mercado de trabajo, como consumidores de bienes y servicios, emisores de remesas, impulsando proyectos empresariales o subiendo peldaños en la escala profesional, su influjo es cada vez más perceptible en todos los sectores económicos.

\section{LA VERTIENTE POLÍTICA}

Si hay un punto en el que coinciden todos los sectores activos de la población hispana, es en la escasa presencia política del conjunto en relación a su población, tanto en la participación en órganos de gobierno, como en el ejercicio del voto que, aunque vaya en ascenso, sigue siendo baja. Y, desde luego, en lo que atañe a la primera, si consideramos los miembros en los órganos legislativos de la nación, resulta claramente escueta: 24 en el Congreso - tras los comicios de 2008- y dos en el Senado. Ello supone el 4\% respecto al total en el primero y un exiguo $2 \%$ en el último. Muy lejos por tanto de su cuota en la población general.

A escala estatal y local, en cambio, sí empiezan a tener cierta influencia allí en donde se concentran, aunque aún no refleje su importancia numérica. Tras la elección de 2008 se contaban 65 senadores y 177 representantes en las distintas Asambleas estatales, con claro dominio de los demócratas, al igual que a nivel federal. En los puestos de cabeza, sin embargo, aún no han superado el nivel anecdótico. Sólo un latino ostenta el grado de gobernador: el demócrata Bill Richardson, en Nuevo México, mientras la cifra de alcaldes en ciudades de más de 100.000 habitantes rondan la veintena. De ahí el enorme eco mediático que suscitó la elección del actual alcalde de Los Ángeles, Antonio 
Villaraigosa (electo el 17 de mayo de 2005) al ser el primer latino en ocupar ese cargo en más de un siglo.

Tan escasa incidencia en el orbe político refleja lo débil que es aún su peso en el electorado. En este orden varios factores limitan y determinan su capacidad de acción. Unos de índole sociodemográfica — edad, ingresos y educación [la variable necesaria y los primeros predictores], puntúan en los rangos más bajos - ; otros legales - alto índice de indocumentados y bajas tasas de naturalización-, más los de índole instrumental y cultural — falta de familiaridad con el sistema político americano y desinterés por las elecciones, entre ellos-. Todo ello se traduce en una débil participación electoral que orilla su peso demográfico.

Pues, si al elevado número de menores de 18 años (15,4 millones en 2007), se unen quienes tienen edad de votar pero no son ciudadanos (otros 14 millones en 2007) ${ }^{25}$, sólo restan unos 16 millones facultados para ello [algo más de un tercio (35\%) del conjunto total y la mitad de quienes cumplen con el requisito «edad»]. Pero pocos se registran para ello y, con frecuencia, aún son menos quienes ejercen finalmente el sufragio, como refleja la tabla 4. En general, el voto latino suele situarse en torno al $6 \%$ del total, lejos, por tanto, de la proporción que supone en la población.

Tabla 4. Participación electoral de la Población hisPana. 2000-2006

\begin{tabular}{|c|c|c|c|c|c|c|c|}
\hline \multirow{2}{*}{ Comicios } & \multirow{2}{*}{$\begin{array}{c}\text { Población de } \\
18 \text { y + años } \\
\text { [miles] }\end{array}$} & \multicolumn{2}{|c|}{ Ciudadanos } & \multirow{2}{*}{$\begin{array}{c}\text { Total } \\
\text { registrados }\end{array}$} & $\begin{array}{c}\% \\
\text { registrados } \\
\text { para votar }\end{array}$ & $\begin{array}{c}\text { Total } \\
\text { votantes } \\
\text { [miles] }\end{array}$ & $\begin{array}{c}\% \text { votantes } \\
(18+)\end{array}$ \\
\hline 2000 & 21.598 & 13.159 & 60,9 & 7.546 & 34,9 & 5.934 & 27,5 \\
2002 & 25.162 & 15.601 & 62,0 & 8.196 & 32,6 & 4.747 & 18,9 \\
2004 & 27.129 & 16.088 & 59,0 & 9.308 & 34,3 & 7.587 & 28,0 \\
2006 & 28.945 & 17.315 & 59,8 & 9.304 & 53,7 & 5.595 & 32,3 \\
\hline
\end{tabular}

Fuente: Oficina del Censo de los EEUU, 2006; 2008d. Cálculos propios.

Ello no obsta para que también a esta arena haya llegado la marea del último censo. Pues, aunque los más de nueve millones de votantes hispanos registrados - la mayoría en 10 estados- no refleje el peso demográfico del conjunto, son cerca de cuatro veces los anotados en 1972 (2,5 millones) y es de esperar que vaya en aumento.

25 Oficina del Censo de los Estados Unidos, 2008a y 2008 b. 
Para ello no sólo tienen a favor el tiempo [que mejorará el factor «edad»]. La amnistía de 1986 - que regularizó a 2,7 millones de inmigrantes -; las medidas antiinmigración de la pasada y presente década, la aprobación de la doble ciudadanía en los países latinoamericanos, el «efecto 11 de septiembre» - que a la ola de patriotismo que generó aunó no pocos temores ante sus secuelas en la política migratoria - y las campañas dirigidas a ese fin, se han reflejado en los índices de naturalización y de votantes. Con lo que resultan, o pueden ser, un elemento decisivo a nivel estatal y local en las zonas donde se concentran.

Además, las bajas tasas de participación electoral y el hecho de que se agrupen en los seis estados que proporcionan dos tercios de los votos exigidos para alcanzar la Casa Blanca les convierte en objeto de deseo para los partidos en liza. Algo que ya avanzaron los comicios de 2000 y vienen ratificando los sucesivos ejercicios. Una publicidad cada vez más específica y sofisticada, reiteradas visitas a los núcleos latinos, la versión en «español» de las respectivas páginas web y su utilización cada vez más habitual en las campañas, convertido en instrumento político, son claro indicio de ello.

Cabe señalar, asimismo, el vasto y rico tejido asociativo existente, que se articula alrededor de un amplio elenco de entidades, más o menos formales, y que informa del interés por ser parte activa de la sociedad y de la conciencia sobre la necesidad de organizarse. Muchas limitan su actividad a EEUU, pero abundan también las que se dirigen o centran su atención en el lugar de origen. Sus fines incluyen desde donaciones y subvención de obras públicas, al orden político (doble nacionalidad, voto en el exterior, etc.).

La arena política se extiende ahora - y en ambos sentidos — por encima de las fronteras nacionales. Políticos norteamericanos viajan a los países de origen de las minorías latinas dominantes, al igual que se han convertido en rutinarias las visitas de dirigentes de estos países a las zonas en las que se concentran los grupos emigrados.

Es evidente el efecto positivo de los viajes de políticos «anglo» a los lugares de origen de las minorías inmigrantes, que suelen ir unidos a alguna aportación material y contar con la presencia de cargos electos de ese origen. En cuanto a los países emisores, la creciente importancia de los emigrados — vía remesas y contribución a proyectos de desarrollo local-, la influencia sobre el voto de los coterráneos y el apoyo financiero a campañas y partidos les convierte en actores relevantes en la política interna, a lo que se suma el valor potencial como aliados y mediadores frente a EEUU. Ello ha impulsado un cambio de orientación hacia éstos que se plasma en una serie de acciones dirigidas a afianzar sus lazos con los países y comunidades de origen. La actividad desplegada es muy abundante e incluye tanto medidas internas — doble ciudada- 
nía, voto en el exterior, etc.- como en EEUU, dirigidas a facilitar la inserción de los emigrados.

Asimismo, y al igual que anotamos en el apartado previo respecto a las actividades económicas transnacionales, la implicación en la política de los países de origen - significada en algunos colectivos - no es un reducto de los miembros marginales, recién llegados o menos educados. Por el contrario, como muestran distintos trabajos ${ }^{26}$, suelen estar asentados en EEUU y poseer suficiente nivel de instrucción formal. Es, de igual modo, independiente de la naturalización y no se opone a la participación en la política en los EEUU. Es más, al igual que ocurre con el resto de asociaciones comunitarias y las instituciones delegadas de países emisores, las filiales de los partidos de origen promueven de modo activo la naturalización entre los inmigrantes y la participación política.

Las facetas que operan en esta vertiente actualizan y refuerzan, en suma, los lazos con el lugar y cultura natal contribuyendo a remarcar unas señas e identidad diferenciadas.

\section{La dimensión expresiva [lengua, identidad y afiliación]}

Cerramos este cuadro esquemático con una breve referencia a los aspectos expresivos y simbólicos de la cultura: la lengua y la autoidentificación o afiliación.

Es bien conocida la tradicional presión de la sociedad americana sobre los inmigrantes para su rápida asimilación en la cultura mayoritaria y la aculturación completa como corolario. La imagen de los agentes del Servicio de Naturalización e Inmigración (INS) alterando los nombres de los recién llegados a su paso por Ellis Island ha quedado grabada en los anales de la historiografía. Pero el marco en el que tiene lugar la nueva ola migratoria $-\mathrm{y}$ la latinización de EEUU- difiere sensiblemente del pasado en muchas vertientes y, entre ellas, en lo que atañe a la posición frente a la diversidad y otras culturas. La lucha de los movimientos en pro de los derechos civiles y el pluralismo cultural, en las que se inserta el Movimiento Chicano, han dejado una amplia huella en la memoria y en el contexto, patente en una mayor tolerancia de las diferencias y un cuerpo legislativo que atiende a los derechos de las minorías. La asimilación, en su sentido fuerte, ha perdido tantos en el camino y se halla ahora - al menos a escala normativa - francamente devaluada. Ello no obsta para que la segregación y discriminación racial siga vigente, al igual que tampoco ha ha-

26 Guarnizo, Portes y Haller, 2003. 
bido mucho avance respecto a las lenguas foráneas que despiertan hoy aún más suspicacia y oposición que antes. Ambas forman parte de los obstáculos y dilemas que deben enfrentar los inmigrantes y sus descendientes en el camino hacia su integración y se oponen al deseo de salvaguardar el legado cultural particular.

La exigencia de aculturación lingüística, se hace patente en las propuestas de los movimientos nativistas del tipo US English - revalidadas a nivel local y estatal en suficientes estados y que han llegado al Congreso ${ }^{27}$-, y la animadversión hacia la educación bilingüe. Una actitud que, dados los muchos elementos, propaganda y resultados que tiene en contra, encuentra amplio eco en no pocos padres hispanos, inquietos por el futuro de los más jóvenes.

No es de extrañar, por tanto, que a partir de la segunda generación se resienta la fluidez en la lengua materna que se acaba postergando frente al inglés de forma más o menos completa. Y así lo corroboró el estudio longitudinal de A. Portes y R. Rumbaut sobre segunda generación en Miami y San Diego, dos áreas de gran densidad de inmigrantes, y la generalidad de los trabajos sobre este punto. Casi la totalidad de los jóvenes encuestados, en el citado estudio, hablaba inglés con fluidez - el 94\% en la primera fase y el 98\% tres años más tarde-, mientras no llegaba al tercio $(29 \%)$ los que podían comunicarse en ambas lenguas al completar secundaria. E igual ocurría a escala de preferencias. El $72 \%$ de los chicos seleccionaba la inglesa en el primer tramo de secundaria y aún subía al $88 \%$ al finalizar ésta a pesar de que en casi todos los hogares incluidos en la muestra se hablara una lengua extranjera ${ }^{28}$.

En estas condiciones lo sorprendente es, pues, que alguna otra lengua logre subsistir de alguna manera. Y en este sentido el español, sin llegar a ser una excepción, se mantiene más que el resto. Ésta es, con diferencia, la que conocen más jóvenes $(56 \%)$ y más utilizan, tanto en el hogar $(35 \%)$ como con los pares

27 El último episodio en esta línea fue la aprobación en el Senado, en mayo de 2006 y dentro del proyecto de reforma migratoria, de dos enmiendas que oficializaban el inglés. La primera - aprobada por 63 vs. 34- lo declaraba «lengua nacional». Y la segunda, impulsada por el senador de origen latino Ken Salazar, que intentaba suavizar el efecto excluyente, afirmaba el inglés como «el idioma común y unificador» de la nación. Aunque ha habido otros momentos en la historia de EEUU en los que se restringió el uso de alguna lengua (en 1879, por ejemplo, California cambió su Constitución para eliminar el «derecho» inherente al uso del idioma español garantizado en el Tratado de Guadalupe Hidalgo, y más tarde, a raíz de la Primera Guerra Mundial, se prohibió el uso del alemán en calles, escuelas e incluso en el teléfono), fue la primera vez que el Senado federal aprobó una propuesta de este tipo y la primera que se debatía en las dos cámaras. En 1996, cuando la Cámara baja aprobó por amplio margen (259 vs. 157) un proyecto similar, el Senado, consciente del veto de Clinton, no llegó a considerarlo.

28 Portes y Rumbaut, 2001. 
$(44 \%)^{29}$. La diferencia con las siguientes en la lista —el tagalo y el vietnamitainforma de la distancia existente (véase tabla 5). El español sigue asimismo al inglés en orden de preferencia, aunque el margen es desmesurado, como refleja la tabla 7 , y se acentúa entre la primera y segunda fase indicando la rapidez del giro lingüístico. Es ésta, de igual modo, la lengua que reúne mayor tasa de bilingües (entre el 39 y el 47\% según nacionalidad), a notable distancia de las dos siguientes [haitiano $(15 \%)$ y chino $(10 \%)$ ]. No es extraño, pues, que el origen latino sea el principal predictor de conservación del idioma: los entrevistados de ese origen tenían un 51\% más de probabilidad de mantener la lengua materna. Y aunque una fracción importante $(65 \%)$ pierde fluidez, aún logra destacarse frente al $90 \%$ de anglófonos que reúnen los otros grupos.

Tabla 5. Conocimiento y uso de las lenguas vernáculas entre los Jóvenes de Segunda GENERACIÓN

\begin{tabular}{|c|c|c|c|c|c|}
\hline \multirow[b]{2}{*}{ Lengua } & \multirow{2}{*}{$\begin{array}{l}\text { Conocida por el } \\
\text { informante [en \%] }\end{array}$} & \multicolumn{2}{|c|}{ Preferida por el informante } & \multicolumn{2}{|c|}{ Utilizada con ... } \\
\hline & & 1992 & $1995-1996$ & $\begin{array}{l}\text {... los padres } \\
(\%)\end{array}$ & $\begin{array}{c}\text {... los pares } \\
(\%)\end{array}$ \\
\hline Creole (Haiti) & 2,7 & 0,5 & 0,2 & 1,3 & 2,1 \\
\hline Español & 55,3 & 14,8 & 6,5 & 34,6 & 43,8 \\
\hline Tagalo & 12,6 & 1,7 & 0,7 & 2,2 & 4,0 \\
\hline Vietnamita & 6,5 & 2,9 & 1,7 & 5,8 & 5,1 \\
\hline
\end{tabular}

Fuente: A. Portes y R. Rumbaut (Legacies, 2001).

Varias razones explican la mejor posición del español, además del diseño de la muestra (efectuada en dos áreas de alta concentración latina). Esto es, junto a la proximidad al inglés, la cifra que reúne en el medio social y escolar - que en su caso suma, al tratarse de una lengua franca para los de ese orbe a diferencia de los asiáticos - y el apoyo de instituciones externas entre las que se incluye una creciente red de medios de comunicación (radio, TV, periódicos, etc.). El esfuerzo paterno se ve así respaldado por un amplio marco externo. Ello no obsta para que en la tercera generación escaseen los bilingües mientras la mayoría —entre el $70 \%$ y el $78 \%$ según varios estudios ${ }^{30}$ - ha consumado el cambio lingüístico.

29 Idem.

30 Véase, entre otros, R. Alba, 2004. Pew Hispanic Center/Henry J. Kaiser F. F., 2002. Rumbaut et al., 2006. 
Aunque no todos los latinos hablen español, es la lengua vernácula que congrega mayor número de hablantes (34,5 millones en 2007 , el $12,5 \%$ de la población), tanto entre los miembros del conjunto de referencia, como ajenos; la única, además del inglés, que está presente en todos los Estados, y la más demandada en todos los niveles de enseñanza.

En cuanto a la afiliación e identidad, es bien conocida la fidelidad que mantienen los miembros de la primera generación a las originales. De ello da cuenta la persistencia de la idea de retorno y las múltiples formas en que se manifiesta el arraigo a las referencias de partida: resistencia a la naturalización, implicación en asociaciones de base comunal, contribución a las zonas de origen, fidelidad a los símbolos y fiestas nacionales, etc. Menos fácil lo tienen los jóvenes que deberán elegir entre las opciones a su alcance, lo que hace su autoidentificación más compleja e inestable. En este sentido, lo más destacado, según el citado estudio de Portes y Rumbaut, es el desplazamiento entre las distintas etiquetas al final de la adolescencia; de signo positivo, para la ligada al origen nacional parental y a la panétnica, y negativo respecto a la identidad estadounidense.

En este sentido, varios factores dificultan una plena identificación con la sociedad americana y contribuyen a reafirmar la originaria. Entre ellos, la discriminación y segregación que padecen como miembros de una minoría étnica y como inmigrantes. Esto puede llevar a procesos reactivos en los que la lengua y cultura materna y la adscripción inicial se convierten en símbolos de orgullo frente a la amenaza externa; es lo que algunos teóricos de las migraciones denominan, etnicidad reactiva. Por otra parte, la rígida estructura racial de la sociedad norteamericana se opone a la tradición mestiza que troquela las sociedades latinoamericanas y a la experiencia acarreada desde el contexto de procedencia. En este orden, la inmigración implica, y en especial para quienes proceden de países caribeños, toparse con el componente racial particular relegado, más o menos parcialmente, en la sociedad de origen. La fractura de la identidad personal y la reelaboración posterior, que sigue a la inmigración, debe contemplar pues este nuevo elemento; la «tercera raíz» como la denominan los académicos dominicanos, para quienes el arribo a EEUU supone el descubrimiento de la propia «negritud». Asimismo, las raíces indígenas coloca a buen número de los otros conjuntos en una posición ambigua en la escala racial acentuando así la percepción de diferencia. La elevada cifra que desecha las etiquetas rotundas en la cuestión de la «raza», en el censo 2000, y opta por «alguna otra» - $42 \%$, frente al $0,2 \%$ entre los «no hispanos»—- parece apuntar en esta dirección. Y así lo corrobora también el elevado índice (59\%) que, en un estudio conjunto del Washington Post, la Fundación Kaiser e investigado- 
res de Harvard, descartaba cualquier similitud tanto con los anglos como con la población afroamericana.

A su vez, el pensamiento multicultural instituye el valor de la diversidad, exaltando la etnicidad y culturas de origen, e impugna — en cuanto horizonte normativo- la asimilación. De ahí que la recuperación de las raíces, no sea ajena al descubrimiento de lo hispano por parte de la población anglo. Esto, unido a la visión positiva del hecho migratorio que distingue a EEUU de los países europeos $-\mathrm{y}$ al hecho positivo de que el migrante de hoy es también ciudadano, y por tanto (eventual) votante mañana - se refleja en la presencia habitual de autoridades en los actos que afirman la identidad particular, en los que se ensalza el apego y fidelidad a la identidad y herencia cultural original. $\mathrm{Y}$, aunque no deje de ser una práctica rutinaria, y con una marcada finalidad electoralista, es evidente que ello no anula el efecto afirmativo contribuyendo a la vez a contrarrestar la etnicidad reactiva.

A modo de conclusión. Los latinos y el futuro demográfico de los Estados Unidos

Diversas razones hacen de la evolución de la población latina en los EEUU un tema de interés y orientan acerca del potencial de la inmigración como factor de cambio. Ésta permite observar asimismo que el proceso de ajuste socio-cultural de la población inmigrante puede adoptar diversos modos en función del contexto y el momento histórico en que tiene lugar, dando lugar a resultados no previstos, o que cuestionan directamente presupuestos y axiomas de los paradigmas teóricos precedentes. La evolución de la población latina en dicho ámbito se convierte así en un test que aportará nuevos datos y ayudará a una mejor comprensión de los procesos de adaptación mutua — de sociedad e inmigrantes - y los cambios — en individuos, colectivos y sociedad - a que dan lugar.

Hay, además, otras dos razones que lo convierten en un hecho histórico y lo dotan de interés sociológico. Una, que por primera vez coinciden en un mismo contexto dos dominios culturales - lo hispano y lo anglo- que difieren en modos de ver y trayectorias y cuya relación histórica se ha articulado en torno a la rivalidad y el conflicto. La otra, porque de igual modo $-\mathrm{y}$ debido al aluvión humano que transporta la corriente migratoria - coinciden ahora en un mismo entorno - lo que implica bajo cierta similitud de circunstanciaslas diversas nacionalidades latinoamericanas. Se trata, pues, de una etapa de tránsito que apunta hacia una nueva configuración social, y probablemente también cultural, de la sociedad estadounidense y de dichos grupos; el preám- 
bulo de un nuevo crisol ${ }^{31}$, de una «nueva síntesis», como recogía el lema general de uno de los escasos congresos celebrados en España sobre esta población.

En las últimas décadas la población latina ha observado un notable desarrollo en los Estados Unidos. En 1980 sólo uno de cada 17 residentes era de origen hispano; en 2007, lo era uno de cada seis. Y según cálculos oficiales, a mediados de este siglo lo será uno de cada tres. Para entonces la población latina habrá agregado más de 87 millones a los que cuenta ahora y contabilizará unos 133 millones.

Ello alterará sustancialmente la composición y estructura étnica y racial de los Estados Unidos, que evidencia ya los primeros signos del cambio. Las minorías, con la latina a la cabeza, constituirán en 2050 más de la mitad de la población nacional, mientras la población blanca-no hispana, históricamente dominante y que en 2000 rondaba el $70 \%$, reducirá su margen y constituirá para entonces algo menos de la mitad. Es decir, Estados Unidos, dejará gradualmente de ser la reverberación transatlántica del humus europeo, un trasunto puntual de la identidad anglosajona, para trocarse en una nación global. De hecho, ya son varios los estados - Hawai, Nuevo México, California y Texas- en los que más de la mitad de su población la componen minorías y pronto se les unirán algunos más, en donde ya rondan o superan el 40\% (Nevada, Maryland, Georgia, Missisipi, Arizona, Nueva York, Florida y Nueva Jersey $^{32}$ ). El cambio repercutirá a escala social, cultural y política y necesariamente debería reflejarse en las prioridades sociales.

Dada la concentración de la población hispana es fácil deducir que será el segmento dominante en no pocas áreas. A nivel local ya ocurre así en distintos condados, ciudades y municipios del sudoeste. Algunos de ellos muy populosos, como el condado de Los Ángeles, en donde los latinos (4,7 millones en 2007) suponen casi la mitad de sus residentes $(47,2 \%)$. Y el proceso seguirá su curso, en particular en esas áreas, a escala estatal, a un nivel más amplio y con antelación al plazo antedicho. California, por ejemplo, el estado más rico y poblado de la unión, se calcula que en 2040 albergará más de 26 millones de latinos, casi la mitad de sus habitantes $(49 \%)^{33}$. En Texas, el segundo en población y el último en consumar la transición a la condición de «mayoría de minorías», se prevé que superen en cifra a la población eurocaucásica antes de 2020 y se conviertan en mayoría en 2035. Ambos reúnen, en conjunto, la quinta parte de la población

31 III Congreso Internacional «Culturas hispanas en los Estados Unidos de América: hacia la nueva síntesis», Barcelona, junio de 1988.

32 Oficina del Censo de los EEUU 2008a.

33 State of California, 2007. 
nacional y aportan más de un tercio de los votos necesarios para la elección presidencial, lo que orienta sobre el alcance del proceso.

Son varias las cuestiones que emergen en este orden. La primera, si la experiencia de la población latina seguirá un patrón similar a la de los europeos y asiáticos o replicará el de los afro-americanos. Algunos segmentos de la población latina, como los cubanos y sudamericanos, con más capital humano y recursos socioeconómicos de partida, están experimentando una movilidad ascendente, lo que evoca el itinerario de los primeros. Pero no parece tan claro que la pauta sea extensiva a otros grupos. Mexicanos, puertorriqueños, dominicanos y otros grupos, menos instruidos y más condicionados por el color y los antecedentes indígenas, siguen, con frecuencia, un camino inverso. Sus limitados recursos familiares y sociales y el escaso apoyo social prolonga el déficit educativo en las nuevas generaciones que siguen ancladas en los peldaños más bajos de la escala socioeconómica.

La experiencia de la inmigración ha afectado significativamente, y aún condiciona, la trayectoria de los latinos en los Estados Unidos. Su persistencia asegura la continuidad del español y de las culturas latinas en suficiente medida, mientras la mezcla de asentados y recién llegados, realza la diversidad tanto inter como intragrupos. En su desarrollo, la población latina está contribuyendo a difuminar diversas barreras sociales que delimitan a propios de extraños. Éstas incumben a la natividad, identidad nacional, raza y lengua. La afiliación al molde bicultural y la extensión del español — dominante en los programas bilingües, la más elegida en secundaria y universidad y que se incorpora de manera paulatina a la cultura dominante - apunta a un itinerario algo distinto a la aculturación tradicional.

Pero con independencia de los rumbos que sigan, es indudable que la evolución de los hispanos - la nueva cara de "América», como gustan de apostillar los media, líderes y políticos_- jugará un papel importante en el futuro del país.

\section{BIBLIOGRAFÍA}

Alba, Richard, «Language assimilation today: bilingualism persist more than in the past, but English still Dominates», Lewis Mumford Center for Comparative Urban \& Regional Research, Universidad de Albany, Working Paper, diciembre 2004.

Bachu, A. y M. O'Connell, «Fertility of American Women: June 2000», Current Population Reports p20-543RV, Washington D.C.: U.S. Census Bureau, 2001.

Banco Mundial, «Remittances Data» (base de datos disponible en http://econ.worldbank.org/, último acceso 10 de diciembre de 2008). 
Camarota, Steven, «Births to Immigrants in America, 1970 to 2002», Center for Immigration Studies, 2005 (http://www.cis.org/).

Criado, M. Jesús, «Inmigración y población latina: un perfil sociodemográfico», Documentos de Trabajo del Instituto Complutense de Estudios Internacionales (ICEI), Madrid, 2007: 1-43.

Criado, M. ${ }^{a}$ Jesús, «Los hispanos en Estados Unidos», en VV.AA., Anuario 2005. Los Temas y sus Protagonistas, Volumen I, EDP Editores, Barcelona, 2006: 228-253.

De Navas-Walt, Carmen, Bernadette D. Proctor y Jessica C. Smith, Income, Poverty \& Health Insurance in the United States 2007. U.S. Census Bureau, Current Population Reports, P60-235, U.S. Government Printing Office, Washington, DC, 2008.

Gibson, C. y K. Jung, «Historical Census Statistics on Population Totals By Race, 1790 to 1990, and By Hispanic Origin, 1970 to 1990, For The United States, Regions, Divisions, and States», Population Division Working Paper $n .^{\circ} 56$, Oficina del Censo de los EEUU, 2002. (http://www.census.gov/population/)

Gibson, C. y K. Jung, «Historical Census Statistic on the Foreign-Born Population of the United States 1850-2000», Oficina del Censo de los Estados Unidos. División de Población, Population Division Working Paper n. ${ }^{\circ}$ 81, 2006. (http://www.census.gov/population/www/documentation/twps0081/twps0081.pdf).

Guarnizo, L. E., A. Portes y W. Haller, «Assimilation and Transnationalism: Determinants of Transnational Political Action among Contemporary Migrants», American Journal of Sociology, Volume 108, Number 6 (May 2003): 1211-48.

Hoefer, M., N. Rytina y B. Baker, «Estimates of the Unauthorized Immigrant Population Residing in the United States: January 2007», U.S. Department of Homeland Security, 2008 (http://www.dhs.gov, último acceso 10/10/2008).

Humpheys, J, «The Multicultural Economy 2007», Georgia Business and Economic Condition, Vol. 67, N. ${ }^{\circ}$ 3, Athens (Georgia), 2007.

Oficina del Censo de los Estados Unidos, Division de Población, Annual Estimates of the Population: April 1, 2000 to July 1, 2007 (NC-EST2007), 2008a (www.census.gov)

Oficina del Censo de los Estados Unidos, Encuesta de la Comunidad Estadounidense 2007, 2008b (www.census.gov)

Oficina del Censo de los Estados Unidos, National Population Projections: 2010 to 2050 (NP2008). 2008c (www.census.gov Datos difundidos en agosto de 2008.

Oficina del Censo de los Estados Unidos, «Voting and Registration in the Election of November 2006», 2008d.

Oficina del Censo de los Estados Unidos,Estimaciones Anuales de Población 2005, 2006a (www.census.gov). 
Oficina del Censo de los Estados Unidos, Encuesta de la Comunidad Estadounidense 2005, 2006b.

Oficina del Censo de los Estados Unidos, «Vital Statistics», Statistical Abstract of the United States: 2007, 2007.

Oficina del Censo de los Estados Unidos, «Voting and Registration in the Election of November 2004», 2006c.

Massey, D., Jorge Durand y Nolan J. Malone, Beyond Smoke and Mirrors. Mexican Immigration in an Era of Economic Integration, Nueva York, Russel Sage Foundation, 2002.

Passel, J., «Unauthorized Migrants: Numbers and Characteristics», Pew Hispanic Center, 2005 (www.pewhispanic.org).

Passel y Cohn, «Trends in Unauthorized Immigration: Undocumented Inflow Now Trails Legal Inflow», Pew Hispanic Center, 2008 (www.pewhispanic.org).

Pew Hispanic Center/Henry J.Kaiser Family Foundation, 2002 National Survey of Latinos, 2002 (www.pewhispanic.org).

Planty, M., W. Hussar, T. Snyder, S. Provasnik, G. Kena, G., R. Dinkes, A. Kewal Ramani y J. Kemp, The Condition of Education 2008 (NCES 2008-031), Washington, DC., National Center for Education Statistics, Institute of Education Sciences, U.S. Department of Education, 2008.

Portes, Alejandro, «La nueva nación latina: inmigración y población», La Vanguardia Dossier, 13, Barcelona, 2004: 6-14.

Portes, A., W. Haller y L. E. Guarnizo, «Transnational entrepreneurs: the emergence and determinants of an alternative form of immigrant economic adaptation», American Sociological Review. Vol. 67, Columbus (Ohio, EEUU), 2002: 278-298.

Portes, A. y R. Rumbaut, Legacies. The Story of the Second Generation, Nueva York, Universidad de California y Russel Sage Foundation, 2001.

Rumbaut, R., D. Massey y F. Bean, «Linguistic life expectancies: Immigrant language retention in Southern California», Population and Development Review 32 (3): 447-460, Nueva York, 2006.

State of California, Department of Finance, Population Projections for California and Its Counties 2000-2050, by Age, Gender and Race/Ethnicity, Sacramento (CA), 2007.

Suárez-Orozco, M. y M. Páez, «The Research Agenda», M. Suárez-Orozco y M. Páez (eds.), Latinos. Remaking America, Berkeley, Univ. de California y David Rockefeller Center for Latin American Studies (Harvard University), 2002: 1-37. 


\section{CROSSING BORDERS. RECONSIDERATION OF THE LATIN AMERICAN CHARACTER IN THE NORTH OF RIO GRANDE}

This paper describes the evolution and characteristics of the population of Hispanic origin living in the United States. Its evolution in the last decades and the main tendencies observed are analysed from official data and other secondary sources. This will enable to outline the prevailing profile of this varied group, their social position and the processes they are immersed in. The generated dynamics affect both poles (immigrants and their offspring and the American world) and aim to reconsider the Latin American character in this context.

Key words: International migration, Hispanic population, assimilation, cultural plurality, United States, Latin America. 